\title{
Pendidikan Islam dalam Era Revolusi Industri 4.0
}

\author{
Adun Priyanto \\ IAIN Purwokerto, Indonesia \\ adoncrush@gmail.com
}

\begin{abstract}
The challenges facing the world of education are becoming increasingly complex, education is said to adjust to the existence of an era of technological progress, technology integration. This means that the modernization of Islamic education based on character education becomes a necessity to create education in accordance with the needs of the millennial era. This study aims to determine the problems of Islamic education that are happening and how the challenges of Islamic education in the future. Then how is the solution for the world of Islamic education to be able to compete and even become a reference in the implementation of education in Indonesia. The research method uses literature study by collecting data from documentation using descriptive-analysis method. The results of the study can be concluded, Islamic education transformation is greatly required to gain solutions from the arising crisis and problems. Strengthening the Islamic educational institutions also requires more attention, including strengthening the Islamic educational management, Islamic educational leadership, and educational policy reform which is intended to create an intact generation as well as excellent and competitive human resources with creativity, innovations, character, independence, nationality, and religiously in facing Era 4.0 where humans are expected to be fast, accurate, effective, and efficient.
\end{abstract}

Keywords. Islamic Educations; The Industrial Revolution Era 4.0.

\begin{abstract}
Abstrak. Tantangan yang dihadapi dunia pendidikan menjadi semakin kompleks, pendidikan di tuntut untuk menyesuaikan dengan keberadaan era kemajuan teknologi, integrasi teknologi. Modernisasi pendidikan Islam berbasis pendidikan karakter menjadi keniscayaan untuk menciptakan pendidikan yang sesuai dengan kebutuhan zaman generasi milenial. Penelitian ini bertujuan mengetahui permasalahan pendidikan Islam yang sedang terjadi dan bagaimana tantangan pendidikan Islam kedepan. Kemudian bagaimana solusi bagi dunia pendidikan Islam agar mampu bersaing bahkan menjadi acuan dalam pelaksanaan pendidikan di Indonesia. Metode penelitian menggunakan studi literatur dengan mengumpulkan data dari dokumentasi menggunakan metode deskriptif-analisis. Transformsi pendidikan Islam diperlukan untuk membawa keluar dari krisis dan permasalahan, penguatan lembaga pendidikan Islam juga perlu mendapatkan perhatian, meliputi penguatan manajeman pendidikan Islam, penguatan kepemimpinan pendidikan Islam, dan reformasi kebijakan pendidikan, dengan dengan tujuan untuk membentuk generasi seutuhnya dan manusia unggul yang berdaya saing yaitu manusia kreatif, inovatif, berkarakter, mandiri, cinta tanah air dan religious untuk menghadapi Era 4.0 di mana manusia dituntut serba cepat, tepat, efektif dan efisien.
\end{abstract}

Kata Kunci. Penddidikan Islam; Era Revolusi Industri 4.0.

Copyright (C) J-PAI: Jurnal Pendidikan Agama Islam. All Right Reserved.

This is an open-access article under the CC BY-SA license

(https://creativecommons.org/licenses/by-sa/4.0/).

Correspondence Address: jpai@uin-malang.ac.id 


\section{A. PENDAHULUAN}

Pendidikan Islam (pesantren) merupakan pendidikan tertua di Indonesia dengan sejarahnya (Faizin, 2017; Gazali, 2018; Rahman, 2019), telah mengalami masa yang panjang dan bertahan dengan metodenya bahkan hingga saat ini. Dewasa ini, sedang diuji dengan hadirnya abad digitalisasi dan perubahan teknologi yang begitu cepat, inilah permasalahan baru yang harus di hadapi disamping permasalahan klasik yang ada. Menurut Mustofa Rembangy (2010): "permasalahan pendidikan Islam dipengaruhi oleh faktor internal meliputi relasi kekuasaan dan orientasi pendidikan, aspek kurikulum, pendekatan/metodologi pembelajaran, professionalitas SDM, biaya, dan lingkungan pendidikan. Sedangkan faktor eksternal, yaitu fenomena globalisasi-multikultural, kemiskinan, dan kebijakan pemerintah".

Menurut Para ahli dalam Umiarso dan Asnawan (2017) mengidentifikasi permasalahan yang muncul disebabkan oleh: Pertama, Orientasi format kurikulum yang tidak jelas. Kedua, Tataran implementasi yaitu mempelajari ilmu klasik dan sehingga tidak menyentuh ilmu modern. Ketiga, Terbuai dengan kejayaan lalu di. Sehingga sulit melakukan pembaruan (Nanik Masruroh dan Umiarso, 2011, p. 12), akibatnya stakeholder hanya melakukan westernisasi pendidikan Islam dengan cara mengambil konsep pendidikan barat dengan tidak hati-hati dan melakukan penyesuaian sekedarnya (Umiarso dan Asnawan, 2017). Keempat, Model pembelajaran mempertahankan pendekatan intelektual verbalistik dan menegasi interakasi edukatif dan komunikasi humanistik yang bersifat doctrinal (Nanik Masruroh dan Umiarso, 2011). Sehingga peserta didik kesulitan mengembangkan kemampuan berpikir kritis dan kreatif sesuai tuntutan pendidikan modern (Sulistyowati \& Rohman, 2020) karena interkasi guru dan murid seperti subjek dan objek. Kelima, esensi ajaran Islam dimaknai sebatas masalah syariah, muamalah, dan akidah, sehingga kurang merespons realitas sosial. Akibatnya peserta didik jauh dari lingkungan sosio-kultural mereka. Keenam, persoalan konseptual-teoritis. Dikotomi antara agama dan bukan agama, wahyu dan akal, dunia dan akhirat. Ketujuh, materi dan bahan ajar tidak sesuai pekembangan literature zaman. Kedelapan, metode pembelajaran menitik beratkan hafalan bukan proses berfikir logis. Kesembilan, kesalahan perspektif pendidik terhadap peserta didik. Sehingga proses pendidikan disorientasi pada penemuan jati diri peserta didik cerdas, kreatif, kritis. Kesepuluh, rendahnya kualitas intelektual, teknologi, dan professionalitas tenaga pendidik. Kesebelas, bentuk kurikulum sekuler namun sedikit diwilayah ilmu terapan, skill atau teknologi, dan kajiannya pada tataran rasional, intelektual, etis, dan irfani. Kedua belas, terjadinya imperialism epistimologi barat terhadap pemikiran Islam. Ketiga belas, Pendidikan Islam pada umumnya dianggap sebagai pendidikan kelas dua (second class).

Permasalahan yang membuat miris terjadi kasus korupsi dalam lembaga pendidikan (Widianto, 2015) bahkan pada kementerian penyelenggara pendidikan (Hairani, 2013; Prabowo, 2019). Disebabkan karena (1) lemahnya kualitas SDM, (2) Disintegritas penyelenggara pendidikan (Rembangy, 2010). (3) Manajemen Pendidikan yang buruk. (4) Kapitalisasi pendidikan. Dan pada tataran peserta didik terjadinya penetrasi dekadensi moral, disebabkan fenomena budaya baru sebagai akibat globalisasi dan kecanggihan teknologi (Basyari, 2019) yang tidak sesuai dengan norma yang ada dimasyarakat. Akibatnya banyak terjadi kasus asusila dikalangan remaja/pelajar, narkoba, tawuran antar pelajar, geng motor, penyalahgunaan konten, klick and share-hoax di media sosial, menciptakan konten hiburan aplikasi video yang tidak berfaedah dan meresahkan.

Di lain sisi Masyarakat juga menuntut kepada pendidikan Islam terhadap output peserta didik, yaitu manusia unggul yang mempunyai jiwa kreatifitas tinggi, produktif, kompetitif dan religius yang menjadi katalisator dari ketiga jiwa entrepreneur yang ditumbukan siswa dalam dunia pendidikan. 
Adun Priyanto: Pendidikan Islam dalam Era Revolusi Industri 4.0

Beranjak dari permasalahan kompleks diatas, tujuan yang ingin disampaikan adalah bahwa permasalahan pendidikan Islam tidak boleh dipandang sebagai hal yang biasa oleh stakeholder yang ada agar pendidikan Islam mampu bersaing dan menjadi acuan baru dalam pelaksanaan pendidikan di tanah air. Sehingga pendidikan yang membentuk insan kamila seperti cita-cita pendidikan dapat tercapai.

\section{B. METODE}

Metode Penelitian menggunakan studi kepustakaan (library research) dengan menghimpun data dari tulisan-tulisan (literasi) yang mempunyai kaitan dengan topik yang dibahas, yaitu Pendidikan Islam dalam Era 4.0. Data-data tersebut peneliti ambil dari dokumentasi yang bentuk buku, jurnal penelitian, dan artikel-artikel yang mendukung. Metode pembahasan menggunakan metode deskriptif-analisis, yaitu menjelaskan serta mengelaborasi ide-ide utama yang berkenaan dengan topik yang dibahas. Kemudian menyajikannya secara kritis melalui sumber-sumber pustaka primer maupun skunder yang berkaitan dengan tema.(Sugiyono, 2005; Sukmadinata, 2005; Trianto, 2011)

\section{HASIL DAN PEMBAHASAN}

\section{Era Revolusi Industri 4.0}

Istilah "Revolusi Industri" diperkenalkan oleh Friedrich Engels dan Louis- Auguste Blanqui di pertengahan abad ke-19 (Priatmoko, 2018). Pada Fase 1.0, penemuan mesin yang menitik beratkan pada mekanisasi produksi. Fase 2.0 pada etape produksi massal yang terintegrasi dengan quality control dan standarisasi. Fase 3.0 keseragaman massal yang bertumpu pada integrasi komputerisasi. Fase 4.0 digitalisasi dan otomatisasi, perpaduan internet dengan manufaktur.

Era Revolusi Industri 4.0, disebut juga era cyber atau era tanpa sekat dan batasan ruang dan waktu, merangsang sekaligus menumbuhkan kemajuan sains-tecnology yang menghasilkan penciptaan mesin pintar, robot otonom, bahkan Artificial Inteligent (AI). Era ini banyak memberikan kesempatan-kesempatan baru dalam segala bidang dan sekaligus melahirkan tantangan-tantangan yang kompleks dan sulit. Sehingga menuntut kualitas SDM yang menguasai ilmu pengetahuan dan juga dapat memecahkan masalah-masalah dalam kehidupan masyarakat (Rembangy, 2010).

Generasi di era milenial merupakan "generasi internet" yang berinteraksi lebih dinamis dan memiliki ruang lingkup keterhubungan tanpa batas (Rahman, 2019). Mereka setiap hari hidup dan bertumbuh dengan dunia digital, sangat akrab dengan teknologi modern seperti tablet, gadget, portable computer dan sistem operasi android, IoS, sebagai samudra informasi yang dapat diakses kapan saja dan dimana saja. Asef Bayat dan Linda Herrera (2010) dalam Rahman (2019a) Informasi Teknologi (ICT) yang berasal dari handphone yang tersambung ke internet telah merubah pola belajar, budaya, kehidupan sosial, cara pandang kedepan dan keterlibatan politik .

Dengan perubahan sikap sosiologis-psykologis masyarakat, maka pendidikan harus melakukan revolusi untuk menuntut cara-cara baru dalam penguasaan ilmu pengetahuan dalam pembelajaran. Don Topscot dalam (Jarkasih, 2019; Rahman, 2019) menyatakan ada tiga unsur proses belajar yang asing di dalam budaya lama, yaitu: interaktif, partisipatif, dan diskursus. Oleh karena itu, perlu pola baru pembelajaran yang terbentuk akan memudahkan peserta didik dan guru. Diharapkan siswa lebih termotivasi, berpikir dinamis, kreatif, inovatif dan pembelajaran menjadi lebih menyenangkan.

Pembelajaran dengan teknologi internet menjadikan peserta didik lebih aktif, peserta didik dapat berinteraksi langsung dengan sesama pembelajar, maupun dengan pakar-pakar di bidangnya. Menurut Tilaar (2002) Proses pembelajaran yang tidak di batasi oleh ruang kelas, peran guru sebagai fasilitator, sumber belajar bisa dari mana saja, 
pembelajaran menjadi proses menganalisis informasi yang didapatkan, (Giarti \& Astuti, 2016; Hasanah, 2014; Khoeriyah, 2019; Lince, 2016; Mumtahanah, 2014; Nu'man, 2016; Sulistyowati \& Rohman, 2020; Wulantina, 2018).

Tentu saja pengaruh era disrupsi tidak hanya kepada proses belajar mengajar dikelas saja, namun kepada seluruh sistem pendidikan lewat penggunaan Sistem Informasi Manajemen di sekolah. Seperti pusat layanan pendidikan berasis digital di sekolah atau one-stop digital education managemen system yang di gunakan untuk seluruh kegiatan dari mulai kurikulum, guru, pembelajran, laporan keuangan, penilaian sampai dengan pengelolaan bahan ajar, dan sarana prasarana. Dan sekaligus sebagai dashboard informasi ke publik tentang program dan visi misi madrasah yang di unggulkan.

\section{Penguatan Pendidikan Karakter di tengah Dekadensi Moral}

Pendapat para ahli terhadap pendidikan (paedagogie) secara luas adalah usaha mengembangkan pengetahuan, keterampilan pengalaman, serta kecakapan kepada generasi muda sebagai usaha untuk menyiapkannya agar dapat memenuhi fungsi kehidupannya baik jasmaniah dan rohaniah. Sedangkan dalam arti sempit adalah sekolah atau lembaga pendidikan lain baik formal, maupun informal (Umiarso dan Asnawan, 2017). Aspek-aspek yang biasanya paling dipertimbangkan dalam pendidikan, antara lain : penyadaran, pencerahan, pemberdayaan, dan perubahan prilaku.

Dapat ditarik kesimpulan bahwa pendidikan seharusnya lebih banyak pada proses pengolahan sikap (akhlak) peserta didik, keberhasilan pendidikan bukan lagi pada orientasi kognitif dengan ukuran angka-angka. Namun pada proses bagaimana peserta didik mempunyai akhlak yang mulia, empati, kejujuran, keberanian, dan berkepribadian yang baik, yang ditunjang dengan penguasaan kognitif dan psikomotorik yang baik. atau lebih dikenal dengan pendidikan karakter.

Sebagaimana kita ketahui, Jepang pernah hancur di bom atom namun kemudian cepat bagkit lewat pendidikan karakter yang di tanamkan ke dalam Life skill, tidak hanya dilakukan di sekolah saja melainkan di lakukan di lingkungan keluarga dan masyarakat. Hasil pendidikan karakter sekatsu dan tokatsu (Mulyadi, 2014) yang bertujuan menjadikan manusia seutuhnya (insan kamil) menjadikan Jepang sebagai maju, pekerja keras, kuat, sederhana, memiliki rasa nasionalisme yang tinggi, disiplin, patuh pada aturan, suka bekerjasama (kooperatif), mandiri, dan menghargai orang lain.

Secara harfiah akhlak berarti perangai, prilaku, sikap, tabiat, budi pekerti (Nata, 2018). Menurut Ibn Miskawaih dan al- Ghazali yakni, ekpresi jiwa yang muncul dengan mudah tanpa memerlukan pemikiran dan pertimbangan, artinya bahwa sesuatu dapat dikatakan akhlak apabila telah memiliki lima ciri, yaitu: sudah mandarah daging, sudah mudah dan gampang dilakukan; dilakukan atas kemauan sendiri; dilakukan dengan sebenarnya, diniatkan karena Allah SWT.

Pada dasarnya pendidikan karakter menekankan kepada aspek moral, yang menumbuhkan sikap kepribadian yang religious, moral/budi pekerti serta kepedulian terhadap lingkungan (ciri Insan Kamil). Oleh karena itu harus ditanamkan sedini mungkin dan dilakukan secara berkesinambungan. Umiarso dan Asnawan (2017) mengutip Lickona (1992), menekankan tiga komponen karakter yang baik, yaitu 1) moral knowing, yang terdiri dari (a) moral awareness (kesadaran moral), (b) knowing mora values (mengetahui nilai-nilai moral), (c) perspektif taking (pengambilan pandangan), (d) moral reasoning (alasan moral), (e) decision moral (pembuatan keputusan), (f) self-knowledge (kesadaran diri sendiri). 2) Moral Feeling, yaitu aspek lain yang harus di tanamkan sebagai sumber kekuatan untuk bertindak sesuai dengan prinsip moral, meliputi : conscience (nurani), selfesteem (percaya diri), empaty (merasakan penderitaan orang lain), loving the good 
(mencintai kebenaran), self-control (mampu mengontrol diri) dan humility (kerendahan hati). 3) Moral Action, yaitu kompetensi, keinginan, dan kebiasaan.

Sri Narwanti (2011) menyatakan nilai-nilai karakter yang bersumber dari agama, Pancasila, budaya dan tujuan pendidikan nasional Indonesia, meliputi: Religius, Jujur, Toleransi, Disiplin, Kerja Keras, Kreatif, Mandiri, Demokratis, Rasa ingin tahu, Semangat kebangsaan, Cinta Tanah air, Menghargai Prestasi, Bersahabat/komunikatif, Cinta damai, Gemar membaca, Peduli lingkungan dan sosial, bertanggung jawab.

Pendidikan karakter dalam pendidikan Islam memiliki nilai yang lebih dari sekedar pendidikan moral (benar atau salah), melainkan mengajarkan pemahaman melakukan halhal yang baik. Dalam pendidikan Islam ada dua paradigma besar, Pertama, paradigma yang memandang pendidikan karakter dalam cakupan pemahaman moral yang sifatnya lebih sempit, yang menganggap peserta didik memerlukan karakter tertentu yang hanya tinggal diberikan saja. Kedua, pemahaman dari sudut pandang yang lebih luas, paradigma ini memandang karakter sebagai paedagogi, menempatkan individu yang terlibat dalam dunia pendidikan sebagai pelaku utama pengembangan karakter.

Dengan pendidikan Islam yang berkarakter maka diharapkan dimasa mendatang bangsa ini siap menyongsong pendidikan 4.0 yang menitik beratkan pada keunggulan life skill, agar menjadi bangsa yang berdaya saing (Umiarso dan Asnawan, 2017). Oleh karenanya penguatan pendidikan karakter menjadi sangat penting di era tanpa sekat dan batas, karena karakter menunjukkan jati diri bangsa, kekuatan suatu negara, dan pesatuan dan kesatuan suatu negara serta menjadi makna dari pembentukan insan kamil, sesuai dengan tujuan dari pendidikan nasional itu sendiri.

\section{Konsep Praktek dalam Pendidikan Islam di Era 4.0}

Pendidikan Islam selama ini telah melakukan transformasi pada tataran paradigma, metode dan strategi pengembangan pendidikan Islam agar menjadi kekinian dan relevan dengan situasi dan kondisi global. Dan tetap dalam koridor cita-cita dan tujuan pendidikan yang bersandar pada Al-Qur'an dan Hadits serta berpijak pada tujuan pendidikan nasional, dasar negara dan filosofi. Berpegang pada prinsip al hifzu 'ala qodiimi as shoolih wa al akhzu 'ala jadiidi al aslah (mempertahankan tradisi yang baik dan mengadopsi kebaruan yang lebih baik) merupakan mantra paradigma berkemajuan, kontinuitas, keterbukaan dengan inovasi untuk melakukan transfer of knowledge and technology yang maslahat bagi pengembangan pendidikan Islam (Rahman, 2019).

Dalam kurun waktu 10 tahun terakir pendidikan Islam terus berkembang menjadi role model bagi pendidikan, ditandai dengan pertumbuhan lembaga (Direktorat Jenderal Pendidikan Islam, 2019) bermunculannya sekolah berbasis agama Islam seperti Sekolah Islam Terpadu (Rahman, 2019), Boarding School, Sekolah Berbasis Pesantren Modern, Sekolah Tahfidz. Peralihan perguruan tinggi Islam dari STAIN menjadi IAIN atau dari IAIN menjadi UIN. Tidak hanya perubahan "wajah", konten dan program unggulan juga di tawarkan seperti program pesantren entrepreneurship (Gunawan, 2015), dan lain-lain.

Jika hal ini dilakukan pendekatan proses yang benar maka akan menelurkan lulusan-lulusan yang berjiwa produktif, peneliti, penemu, penggali, pengembang ilmu pengetahuan. Konsekuensi logis dari hal ini, (1) Menghilangkan paradigma dikotomi ilmu agama dan ilmu umum. (2) Mengubah pola pendidikan Islam indoktrinal menjadi pola pendidikan pastisipatif. (3) Mengubah paradigma ideologis menjadi paradigma ilmiah yang berpijak pada wahyu Allah swt. (4) Perlu dilakukan rekonstruksi kurikulum.

Paradigma pendidikan Islam lebih cenderung mengorientasikan diri pada bidang humaniora dan ilmu-ilmu sosial, padahal sains (fisika, kimia, biologi dan matematika) modern dan pengembangan teknologi canggih mutlak diperlukan. Sains ini belum mendapat apresiasi dan tempat yang sepatutnya dalam sistem pendidikan Islam (Azra, 
2014). Artinya integrasi pendidikan Islam dalam prespektif trasnformasi menuju pendidikan Islam berkualitas memadukan sains, spiritual dengan pendidikan karakter sebagai ciri khas suatu bangsa mutlak diperlukan. Pendidikan dalam agama Islam sendiri merupakan integrasi antara kekuatan akal (rasional), empiris, dan bersumber pada wahyu yang berasal dari Al-Qur'an dan Hadits.

Trend pendidikan kembali kepada religiusitas (Umiarso dan Asnawan, 2017) dengan diberikan sentuhan wawasan global, maka generasi Islam harus disiapkan untuk persaingan konstalasi global. Sehingga transformasi pada tujuan pendidikan Islam tidak lagi menciptakan para pekerja saja, namun manusia yang mampu bersaing (Azra, 2014; Tilaar, 2002) yang menciptakan peluangnya (lapangan kerja) sendiri dengan dasar inovatif, kreatif, berkarakter dan berjiwa entepreneurship (Rembangy, 2010). Sehingga berdampak langsung kesejahteraan, kemajuan, kemandirian ekonomi bangsa.

Perubahan dalam pendidikan Islam secara otomatis akan merubah metode dalam pengajaran dan pembelajaran yang dilakukan terhadap peserta didik, perubahan itu meliputi Pertama, Pembelajaran yang kritis dan kreatif dengan problem solving, karena dalam kehidupan manusia diperlukan kemampuan menganalisis, mencari jalan mengatasinya, serta mencoba mencari jalan pemecahan yang dirumuskan (trial and error). Pendidik sebagai fasilitator, pembimbing, motivator, dan penggerak menuju pembelajaran yang dialogis. Sementara peserta didik adalah sebagai subjek aktif, partner belajar, dan individu yang mempunyai pengalaman.

Kedua, merubah watak subyek dalam pembelajaran. Paradigma guru sebagai centered learning harus dirubah menjadi guru sebagai professional yang membimbing dan mengarahkan pembelajaran pada siswanya agar mampu menyampiakn pendapat, berfikir sistematis, tampil percaya diri, dan mampu memecahkan masalah dengan pengetahuan yang dimilikinya. Ketiga, sumber pembelajaran tidak terpaku pada buku-buku teks saja, namun bisa pada pengalaman yang dialami siswa, internet, media cetak, elektronik, atau media lainnya (Rembangy, 2010)

Terkait dengan hal tersebut, Drijvers, Boon, and Van Reeuwijk (2010) mengemukakan tiga fungsi dedaktik dari teknologi dalam Pembelajaran Pendidikan Islam, yaitu: (1) Technology for doing, berfungsi sebagai alat pengganti media kertas dan pensil dalam kegiatan pembelajaran. (2) Technology for practicing skills, berfungsi sebagai lingkungan belajar untuk mengasah keterampilan dalam, (3) Technology for developing conceptual understanding, berfungsi sebagai lingkungan belajar untuk mengembangkan pemahaman konseptual. Jika teknologi di integrasikan dengan baik ke dalam pembelajaran, akan memunculkan pola pembelajaran yang baru, kekinian dan menyenangkan. Amin Abdullah menyebut "creative imagination" merupakan bagian dari cara mempertemukan ide-ide, bahkan dua konsep framework yang berbeda, sehingga tersusun menjadi konfigurasi yang fresh (Abdullah et al., 2014).

Menurut H.A.R. Tilaar (2002, pp. 151-156) untuk menghadapi era globalisasi tersebut perlu dilakukan revolusi pendidikan di Indonesia, bidang-bidang yang perlu direvolusi adalah : (1) Pendidikan sains, pelajar Indonesia banyak menjuarai kompetisi sains dunia, olimpiade, dan robotic. Namun berdasarkan tes PISA (The Programme for International Student Assessment) tahun 2019, namun kualitas literasi, sains, dan matematika jauh dibawah Tiongkok, Singapura, dan Maccau (Harususilo, 2019). (2) Pendidikan Kreatifitas. Di era lautan informasi diperlukan sikap saring informasi, dan menumbuhkan ide-ide yang baru. Jepang dan Singapura mengedepankan pendidikan kratifitas bagi para pelajar, sehingga mereka menjadi negara yang maju tanpa sumber daya alam yang melimpah. (3) Pendidikan digital, menggunakan teknologi informasi yaitu computer dan program aplikasi (Kurniawan, 2019) yang terdapat didalammya. (4) 
Adun Priyanto: Pendidikan Islam dalam Era Revolusi Industri 4.0

Pendidikan Tinggi, lembaga ini memiliki peran penting dalam pemeliharaan, pengembangan, dan pelopor aplikasi ilmu pengetahuan.

Modernisasi pada pendidikan menjadi hal yang sia-sia jika tidak di dukung kompetesnsi pendidik, karena mereka merupakan ujung tombak pelaksanaan pendidikan. Untuk itu, pendidik akan dituntut : Pertama, memiliki penguasaan teknologi digital (Tilaar, 2002). Kedua, Agen transformasi kebudayaan. Ketiga, Pengembangan pedagogis (Lince, 2016). Keempat, Kompetensi kepribadian-sosial. Kelima, Pengembangan Profesionalitas. Keenam, inovatif-kreatif-adaptif (Umiarso dan Asnawan, 2017). Selain itu penguatan lembaga pendidikan Islam juga perlu mendapatkan perhatian, meliputi penguatan manajeman pendidikan Islam, penguatan kepemimpinan pendidikan Islam, dan reformasi kebijakan pendidikan dengan mengacu pada kurikulum pendidikan global yang sudah teruji keberhasilannya dan di integrasikan ke dalam kurikulum pendidikan Islam.

Wawasan kebangsaan (nasionalisme) yang diintegrasikan dalam setiap pelajaran dengan penanaman sikap cinta tanah air, budaya, bahasa, adat istiadat dan menjadi agen penjaga kelestarian kesatuan dan persatuan bangsa lewat wawasan kebangsaan. Peserta didik dapat mengaplikasi dalam pergaulan antar siswa, siswa dengan guru, siswa dengan karyawan dan masyarakat serta sebaliknya. Hal ini diperlukan karena kehidupan masyarakat milenial yang tanpa tapal batas negara (border less).

Oleh karena itu pendidikan Islam bertranformasi dengan diorientasikan kepada pendidikan karakter. Penerapan metode pendidikan karakter bagi anak, menurut AlGhazali (Latif, 2016) dengan: (1) Ceramah, (2) Penuntunan dan hafalan, (3) Diskusi, (4) Bercerita, (5) Keteladanan, (6) Demonstrasi, (7) Rihlah (perjalanan untuk mendapatkan pendidikan akhlak), (8) Pemberian tugas, (9) Mujahadah dan riyadhoh, (10) Tanya jawab, (11) Pemberian hadiah dan hukuman. Sedangkan menurut Ratna Megawangi, penerapan metode pendidikan karakter dilakukan dengan mengetahui, mencintai, menginginkan dan mengerjakan (knowing the good, loving the good, desiring the good, and acting the good), karakter adalah sesuatu yang ada yang harus diketahu dicintai diinginkan dan dikerjakan.

Pelaksanaan pendidikan karakter di madrasah dapat dilakukan dengan metode (1) Mengajarkan, yaitu memberikan langsung pengertian atau mengundang pembicara. (2) Keteladanan, pembelajaran efektif pada anak adalah dengan melihat, menganalisa dan meniru. (3) Menentukan prioritas, agar dievaluasi hasilnya dengan menetapkan karakter standar, yang harus dipahami oleh anak didik, orang tua dan masyarakat. (4) Praksis prioritas, pendidikan bukan hanya ilmu pegetahuan dan ketrampilan, namun nilai-nilai keutamaan dalam kehidupan masyarakat seperti membiasakan kesopanan dan kejujuran. (5) Refleksi, kesempatan siswa dalam menyampaikan pemahaman karakter melalui tulisan yang bisa di akses orang lain (Koesoema, 2010).

Perubahan kurikulum di sekolah Islam dilakukan dengan dengan membagi menjadi tiga kelompok: (1) Kelompok sains, (2) Kelompok bahasa dan keterampilan, (3) Kelompok karakter dan pendalaman agama. Kelompok Mata pelajaran sains diantaranya matematika, ipa terpadu (biologi, fisika, kimia), ips terpadu (sejarah : dunia, indonesia dan sejarah Islam, ekonomi, dan geografi).

Kelompok Bahasa dan Keterampilan meliputi: Bahasa Indonesia, Bahasa Inggris, Bahasa Asing: Arab, Mandarin atau Bahasa internasional lain sebagai pilihan, Bahasa Lokal, merupakan mata pelajaran implementatif yang dalam lingkup sekolah, misalnya hari senin seluruh warga sekolah wajib menggunakan Bahasa Indonesia, selasa Bahasa inggris, dan seterusnya. Sedangkan keterampilan, meliputi pengoprasian program aplikasi, komputasi, jaringan, teknologi sederhana dan robotic, menjadi ekstrakurikuler pilihan yang di wajibkan selain juga olahraga, seni dan budaya kearifan lokal.

Kelompok karakter dan pendalaman agama penekanannya pada praktek dalam keseharin peserta didik seperti penerapan sifat siddiq, tabligh, fathonah, amanah dalam 
pergaulan, sikap warga negara yang baik yang dilandasi dengan sikap religious dalam keseharian, dan menerapkan sikap melaksanakan ibadah sehari-hari baik di lingkungan sekolah, di rumah dan di masyarakat. Di madrasah sendiri, porsi waktu pembelajaran untuk mata pelajaran kelompok keagamaan (Akidah Akhlak, Fiqih, Qur'an Hadits, dan Sejarah Islam) sangat sedikit yaitu 8 - 12 jam pelajaran per minggu. Porsi yang sedemikian itu dengan asumsi bahwa siswa di rumah juga menempuh pendidikan agama di jalur informal, seperti madin, pengajian di masjid, di surau/musholla, dan tokoh agama setempat. Jika madrasah tersebut terintegrasi dengan pondok pesantren mungkin tepat jika sebaliknya, maka output keilmuan agama belum memenuhi harapan.

Pendidikan bukan lagi berorieantasi pada nilai kelulusan tetapi hasil peniliaian komprehensif meliputi penguasaan sains, bahasa dan keterampilan, karakter serta ilmu keagamaan. Membekali peserta didik dengan life skill meliputi jiwa entrepreneurship, kreatif, inovatif dan generasi mandiri yang dapat menyelesaikan problem dalam kehidupan, menciptakan lapangan pekerjaan dengan ide-ide orisinalnya.an.

\section{KESIMPULAN}

Pendidikan harus melakukan transformasi, Para stakeholder Pendidikan Islam harus melakukan perubahan pada wajah dan muatan kurikulum sesuai dengan tuntutan zaman sekaligus sebagai benteng pertahanan menghadapi dekadensi moral. Perubahan content akhlaq pendidikan karakter dengan keunggulan daya saing, kognitif, afektif, psycomotoric dan spiritual. Serta pembentukan peserta didik yang inovatif, kreatif, demokratis, berkarakter, berjiwa entrepreneur dan religious.

Transformasi pendidikan Islam meliputi: (1) Perbaikan aturan-aturan yang berlaku, (2) Pendidikan berorientasi kebutuhan masa depan, (3) Peninjauan dan perbaikan Kurikulum, (4) Peningkatan Mutu Manajemen Madrasah, (5) Peningkatan Kapasitas dan Kapabilitas Kepemimpinan Madrasah, (6) Peningkatan Kompetensi guru, (7) Keterlibatan Masyarakat dalam mengembangkan Madrasah, (8) Digitalisasi Pelayanan akademik, administrasi dan pembelajaran.

Hasil penelitian ini merupakan kajian awal tentang landasan teori dan praktik dalam Pendidikan Islam dalam menghadapi Era 4.0, sehingga diperlukan adanya tindak lanjut yang lebih mendalam dalam membahas landasan teori dan praktik dalam Pendidikan Islam dalam menghadapi Era 4.0. Pada penelitian berikutnya bisa menggunakan penelitian studi kepustakaan mengenai landasan teori dan praktik Pendidikan Islan dalam menghadapi Era 4.0 ini dengan membuat penelitian pengembangan ataupun penerapan dengan rujukan pustaka mengenai landasan teori dan praktik Pendidikan Islan dalam menghadapi Era 4.0.

\section{DAFTAR PUSTAKA}

Abdullah, A., Mulkhan, Munir, A., Machasin, Asy'arie, M., Nasution, K., Ilyas, H., \& Faiz, F. (2014). Praksis Paradigma Integrasi-Interkoneksi dan Transformasi Islamic Studies di UIN Sunan Kalijaga.

Azra, A. (2014). Pendidikan Islam: Tradisi dan Modernisasi di tengah Tantangan Milenium III. Jakarta: Prenada Media.

Basyari, I. (2019, December 20). Sebagian Kasus Kenakalan Remaja Dipicu Media Sosial. Kompas.Id. $\quad$ https://kompas.id/baca/nusantara/2019/12/20/sebagian-kasuskenakalan-remaja-dipicu-media-sosial/

Direktorat Jenderal Pendidikan Islam. (2019). Rekapitulasi Data Pokok Pendidikan Islam Madrasah. Kementerian Agama Republik Indonesia, 2019. 
Adun Priyanto: Pendidikan Islam dalam Era Revolusi Industri 4.0

Faizin, I. (2017). LEMBAGA PENDIDIKAN PESANTREN DAN TANTANGAN GLOBAL. Journal of Chemical Information and Modeling, 8(9), 1-58. https://doi.org/10.1017/CB09781107415324.004

Gazali, E. (2018). Pesantren Di Antara Generasi Alfa Dan Tantangan Dunia Pendidikan Era Revolusi Industri 4.0. Oasis, 2(2), 94-109.

Giarti, S., \& Astuti, S. (2016). Implementasi Tqm Melalui Pelatihan Model in House Training Untuk Meningkatkan Kompetensi Pedagogik Guru Sd. Scholaria : Jurnal Pendidikan Dan Kebudayaan, 6(2), 80. https://doi.org/10.24246/j.scholaria.2016.v6.i2.p80-91

Gunawan. (2015). Percikan Pemikiran Pendidikan Islam: Antologi Konfigurasi Pendidikan Masa Depan (Gunawan, Ed.; Cet. I). Rajawali Pers.

Hairani, L. (2013). Korupsi di Kementerian Pendidikan Capai Rp 700 M. Tempo.Co, 485097.

Harususilo, Y. E. (2019, December 4). Skor PISA Terbaru Indonesia, Ini 5 PR Besar Pendidikan pada Era Nadiem Makarim. Kompas.id. https://edukasi.kompas.com/read/2019/12/04/13002801/skor-pisa-terbaruindonesia-ini-5-pr-besar-pendidikan-pada-era-nadiem-makarim?page=all

Hasanah, S. I. (2014). Sumber belajar matematika dari lingkungan alam sekitar berbasis pondok pesantren. Interaksi, 9(1), 28-31.

Jarkasih, S. (2019). Education Answers the Millennial Challenge. 374-378. https://doi.org/10.2991/icas-19.2019.77

Khoeriyah, I. N. (2019). Integrasi Islam dan Sains dalam Pembelajaran Pendidikan Agama Islam di SMA Sains Al-Quran Yogyakarta [UIN Sunan Kalijaga]. In UIN Sunan Kalijaga Yogyakarta. https://doi.org/10.1017/CB09781107415324.004

Koesoema, D. A. (2010). Pendidikan Karakter: Stategi Mendidik Anak di Zaman Global. Jakarta: Grasindo.

Kurniawan, S. (2019). Tantangan Abad 21 bagi Madrasah di Indonesia. Intizar, 25(1), 5568. https://doi.org/10.19109/intizar.v25i1.3242

Latif, L. (2016). Pemikiran Imam Al-Ghazali Tentang Pendidikan Akhlak. Universitas Islam Negeri Maulana Malik Ibrahim.

Lince, R. (2016). Strategi Peningkatan Profesionalisme Guru Dalam Menghadapi Tantangan Di Era Digital. Prosiding Temu Ilmiah Nasional Guru (Ting), VIII(November), 164179.

Masruroh, N. dan Umiarso. (2011). Modernisasi Pendidikan Islam - Ala Azyumardi Azra. Jakarta: Arruz Media.

Mulyadi, B. (2014). Model Pendidikan Karakter Dalam Masyarakat Jepang. Izumi, 3(1), 69. https://doi.org/10.14710/izumi.3.1.69-80

Mumtahanah, N. (2014). Penggunaan Media Visual Dalam Pembelajaran PAI. AL HIKMAH Jurnal Studi Keislaman, Volume 4, Nomor 1, Maret 2014, 4.

Narwanti, S. (2011). Pendidikan Karakter: Pengintegrasian 18 Nilai dalam Mata Pelajaran. Familia.

Nata, A. (2018). Pendidikan Islam Di Era Milenial. Conciencia, 18(1), 10-28. https://doi.org/10.19109/conciencia.v18i1.2436

Nu'man, M. (2016). Pembelajaran Matematika Dalam Perspektif Alquran. JPM : Jurnal Pendidikan Matematika, 2(1), 39. https://doi.org/10.33474/jpm.v2i1.205

Prabowo, D. (2019, November 1). Menag Fachrul Razi Singgung soal Korupsi, Ini 4 Kasus di Kemenag Halaman all. Kompas.Com, 1-3.

Priatmoko, S. (2018). Urgensi Pendidikan Islam Dalam Keluarga. Ta'lim, 11(1), 117. https://doi.org/10.32505/at.v11i1.531

Rahman, A. (2019). Pendidikan Islam di Era Revolusi Industri 4.0. Komojoyo Press. https://doi.org/10.5281/zenodo.3376797 
Rembangy, M. (2010). Pendidikan Transformatif: Pergulatan Kritis Merumuskan Pendidikan di Tengah Pusaran Arus Globalisasi. Teras.

Sugiyono. (2005). Memehami Penelitian Kualitatif. Alfabeta.

Sukmadinata, N. S. (2005). Metode Penelitian Pendidikan. Jakarta: Remaja Rosdakarya.

Sulistyowati, E., \& Rohman, F. (2020). Perangkat Pembelajaran Inkuiri Terbimbing Berbantuan Handout Berbasis Potensi Lokal Hutan Mangrove untuk Meningkatkan Kemampuan Berpikir Kritis dan Sikap Peduli Lingkungan. 374-379.

Tilaar, H. A. R. (2002). Membenahi Pendidikan Nasional. Rieneka Cipta.

Trianto. (2011). Pengantar Penelitian Pendidikan bagi Pengembangan Profesi Pendidikan \& Tenaga Kenpendidikan. Kencana Prenada Media Grup.

Umiarso dan Asnawan. (2017). Kapita Selekta Pendidikan Islam: Isu-isu Kontemporer Pendidikan Islam dalam Bingkai Ke Indonesiaan. Kencana.

Widianto, E. (2015). Tak Transparan, Lembaga Pendidikan Suburkan Korupsi. Tempo.Co, 667551. https://nasional.tempo.co/read/667551/tak-transparan-lembagapendidikan-suburkan-korupsi/full\&view=ok

Wulantina, E. (2018). Pengembangan Bahan Ajar Matematika Yang Terintegrasi Nilai-Nilai Keislaman Pada Materi Garis Dan Sudut. Prosiding Seminar Nasional Matematika Dan Pendidikan Matematika, 1(2), 367-373. 